\title{
Adaptation to extreme weather: identifying different societal perspectives in the Netherlands
}

\author{
Eleftheria Vasileiadou • Matthijs Hisschemöller • \\ Arthur C. Petersen - Wilco Hazeleger • \\ Channah Betgen $\cdot$ Iris de Hoog $\cdot$ Erik Min
}

Received: 29 March 2012/ Accepted: 13 April 2013/Published online: 7 May 2013

(C) The Author(s) 2013. This article is published with open access at Springerlink.com

\begin{abstract}
The intensity and occurrence of extreme weather events are expected to change with climate change. This change necessitates adaptive responses to extreme events, which need to take into account different societal perspectives, in order to be robust. In this paper, we explore the perspectives of different social actors in the Netherlands with respect to extreme weather events and ways to adapt to these events. The paper reports on a set of 41 interviews, using the repertory grid technique. The results were analyzed, to identify (a) the perspectives that stakeholders hold as most important for adaptation to extreme weather events; (b) the determinants of differences in perspectives. We find six different perspectives, all of which prioritize different adaptive actions. Producing robust adaptive responses which include different perspectives is therefore not a straightforward matter and is likely to result in win-lose situations. Further, differences in perspectives were not closely related to different sectors the interviewees belonged to. Thus, the traditional approach of involving different sectors to discuss and produce adaptation measures may be too limiting and
\end{abstract}

E. Vasileiadou $(\varangle) \cdot$ M. Hisschemöller · A. C. Petersen Institute for Environmental Studies, VU University Amsterdam, Amsterdam, The Netherlands

e-mail: eleftheria.vasileiadou@vu.nl

\section{A. C. Petersen}

PBL Netherlands Environmental Assessment Agency, Bilthoven, The Netherlands

W. Hazeleger · E. Min

Royal Netherlands Meteorological Institute (KNMI), De Bilt, The Netherlands

W. Hazeleger

WU, Wageningen University, Wageningen, The Netherlands needs to be supplemented to involving actors with different perspectives. The level of concern and level of information influenced the ways interviewees perceive adaptation priorities for extreme weather events. Participation in information events does not always result in perceived need to prepare for extreme events, something that adaptation communication needs to take into account.

Keywords Extreme weather - Perspectives - Adaptation · Repertory grid $\cdot$ The Netherlands

\section{Introduction}

Climate change is expected to have an impact on the likelihood of the occurrence and duration of extreme weather events, such as extreme precipitation, heat waves and extreme drought, but possibly also snow storms, tornadoes and hail; however, the uncertainties involved in these projections are large, in particular for small-scale phenomena such as extreme precipitation, tornadoes (IPCC 2011). For the Netherlands, the Royal Netherlands Meteorological Institute (KNMI) developed four scenarios, each describing a possible future climate within the range of climate-model scenarios of the CMIP3 project (Van den Hurk et al. 2006; Meehl et al. 2007). According to all KNMI'06 scenarios, temperature increases in winter and summer with respect to current climate. For winter, this means less frost and less likelihood of snow, and for summer, this means a greater likelihood of heat waves occurring with possible extreme temperatures (Van den Hurk et al. 2006). All scenarios show that in winter, precipitation will increase, with the largest increase being when the atmospheric circulation becomes more westerly. Because temperatures also increase, this precipitation will 
imply more rain. For summer, the scenarios with a more westerly circulation give a decrease in precipitation, whereas an unchanged circulation leads to wetter summers. In all scenarios, the amount of rain per precipitation event will increase leading to more extreme rainfall events. It is unclear how wind speed or storms will change in the future, because there is a large natural variability in wind speed. In a recent study, no changes of extreme storm changes were found (Katsman et al. 2011).

Understanding the way that individuals relate to and view these extreme weather events is a necessary precondition of developing robust and adequate strategies of adapting to extreme weather events. Robust adaptation measures are defined as independent from different climate change scenarios and as such likely to create win-win solutions (Dessai and Hulme 2004). It is widely agreed that robust adaptation measures need to be developed together with involved social actors, taking into account their perspectives, needs and values (Valkering et al. 2011; Dessai and Hulme 2004; Otto-Banaszak et al. 2011). Identifying the perspectives and priorities of social actors on adaptation measures for extreme weather events is, therefore, of key importance for the success of these adaptation measures (Pahl-Wostl 2002). The current paper investigates the perspectives of social actors from different economic sectors in the Netherlands with respect to adaptation priorities vis-à-vis extreme weather events.

The paper reports on a recent study among Dutch social actors in various relevant sectors. Differences in the perspectives of social actors on weather extremes can be related to the actors' affiliation to specific economic sectors. The assumption so far is that most adaptation plans, measures and policies need to be specific to each socioeconomic sector (de Bruin et al. 2009). Therefore, involving sector-specific stakeholders seems to be the norm in designing adaptation governance, for instance in the UK Climate Impacts Programme and elsewhere (Ford et al. 2010; Reyer et al. forthcoming; Battaglini et al. 2009). However, as yet the predictive value of the actors' affiliation with specific sectors for their perspectives on the risks of weather extremes has not been firmly established (Lowe and Lorenzoni 2007). It may be the case that differences between perspectives cannot be reduced to simple categories such as differences between economic sectors. Consequently, if the sectoral approach is pursued, it may become more difficult to reach convergence on robust adaptation measures. The problems may turn out to be unstructured, that is, featured by uncertainty or even controversy with respect to the relevance of both knowledge (scientific and practical) and values (Hoppe and Hisschemöller 2001).

This can be examined through a research approach that focuses on identifying the underlying broader perspectives that shape social actors' views and opinions rather than focusing on (volatile) opinions and preferences (Hisschemöller and Midden 1999). Such research approach needs to be bottom-up as to avoid ex ante assumptions linking stakeholder views or biases to certain groups or categories, for example, professional affiliation, concern or level of knowledge (van de Kerkhof et al. 2009).

This paper uses such an approach, with the repertory grid technique from construct psychology (Kelly 1955). It addresses the following research questions:Which perspectives on extreme weather events and adaptation are considered the most important by different social actors in the Netherlands? To what extent do actors' perspectives correlate to actor characteristics, such as their affiliation with specific sectors, level of concern and knowledge?

\section{Analytical framework}

By "perspectives," we refer to underlying frames or belief systems that stakeholders use to make sense of their own observations and experiences. Perspectives structure human observations and help people to make sense of their environment. The perspectives we hold often function as filters for new information and knowledge we acquire, which has been recognized and studied extensively in studies of framing environmental (and other social) problems (Hoppe and Hisschemöller 2001; de Boer et al. 2010; Taylor et al. 1988; Hisschemöller 2005). Extreme weather events are by definition low probability but high impact weather events. We expect mostly negative perspectives, that is, that individuals associate mostly risks (and not opportunities) with such events, and their impacts, but do not preclude positive images as well. The perspectives that are the most important when considering adaptation, link the phenomenon under study, here extreme weather events, with possible solutions or human preventive actions.

Therefore, the perspectives we aim to investigate are broader underlying belief systems of individuals and not narrowly defined risk perceptions. Perceptions of climate risk can be understood as perceived seriousness and likelihood of harm resulting from climate change (Patt and Schröter 2008). Even though they are important in identifying how individuals view climate risks, they are also expected to be influenced by heuristics and biases, and thus to be volatile to recently experienced extremes, among other things (Patt and Schröter 2008). We are interested in broader categories including personal relation to the weather extremes, possible risks but also benefits, as well as possibilities for adaptation. These broader categories include elements that individuals themselves find as relevant for weather extremes (i.e., risks and benefits, impacts, adaptation solutions, human action) and not only or exclusively risks. 
Personal construct theory, introduced in construct psychology (Kelly 1955), provides the framework of our study. The fundamental assumption of this framework, and the method associated, repertory grid technique, is that our different perspectives on a topic, for example, extreme weather events, can be identified as bipolar constructs: that is, dichotomies that we use to distinguish different types of extreme weather and relate them to our personal world (e.g., dangerous for me vs. not dangerous; wet vs. dry, etc.). According to the personal construct theory, we make sense of a situation by noting what it is like, and at the same time what it is different to (Fransella et al. 2004). Constructs are a result of one's experiences and examination of people and places. In addition, they frame how individuals view their world and experiences.

There are various reasons for involving social actors in environmental policymaking. For adaptation governance, one major reason is that stakeholders possess the kind of knowledge that is often referred to as tacit, local or practical knowledge, which is supposed to make a contribution to policymaking in addition to formal scientific knowledge (Ziervogel et al. 2006). In practice, when social actors are consulted, it is often done through formal "stakeholders" as high-level representatives of sectoral interests (Vasileiadou 2012; Vasileiadou and Tuinstra 2012). Going beyond this narrow conception of stakeholders, our study addresses both high- and lower-level practitioners.

Even though including social actors have been emphasized in adaptation to extreme events studies, perspectives are under-researched and also under-utilized for adaptation governance. For instance, a previous study emphasized the need for broader mapping of societal perspectives on adaptation as a starting point for designing adaptation measures (Valkering et al. 2011). Yet the same study involved participants who reflected similar perspectives, instead of allowing of diversity of perspectives. Further, studies suggest that there are potential conflicts between adaptation measures (Reyer et al. forthcoming) and conflicting views underlying how climate change is conceptualized (Buys et al. 2012). Nevertheless, the suggestion that different societal actors prioritize different adaptive responses is not been taken as a starting point for designing adaptive responses, nor is it understood as a potential barrier to adaptive action (Runhaar et al. forthcoming). Differences in perspectives may very well suggest that there may be winners and losers from adaptive action, and that adaptation is not always or cannot be a win-win strategy across a whole society.

The following were included in the study as potential determinants of differences in perspectives. As there is a gap in our understanding of broader perspectives of extreme weather events, we draw on literature from climate risk perception on these possible determinants.
Involvement in sectors

We wonder as to whether individuals from different sectors would have different perspectives on extreme weather events and priorities of adaptation.

In a series of interviews with climate change experts about their perceptions of climate change, Lowe and Lorenzoni did not find any influence of institutional affiliation on these perceptions (Lowe and Lorenzoni 2007). However, as stated in the introduction, in most countries, climate change adaptation plans are developed with a sectoral approach (Keskitalo et al. 2012).

\section{Involvement in (previous) events and workshops}

We want to know whether individuals who have been involved in climate change adaptation workshops or events would hold similar perspectives, drawing upon formal knowledge obtained from reports and oral presentations, whereas those who did not participate would draw more upon tacit knowledge and personal experience. Even though workshops and communication events are common in developing adaptation policies, at least in western countries (Rosenzweig et al. 2011; Eakin and Patt 2011), their impact on how participants view extreme weather is not yet established. For instance with respect to flood risk, very few studies have examined the link between flood risk communication and flood individual risk perception (Kellens et al. 2012). There is some indication that risk communication (for instance through workshops and focus groups) has only weak effects on the flood risk perceptions of individuals (Terpstra et al. 2009).

\section{Level of information}

We like to find out as to whether different level of information among interviewees correlates to differences in perspectives on extreme weather events. Previously, it was suggested that the amount of information of individuals is one of the determinants of experienced or perceived dangerous climate change (Dessai et al. 2004). A review of flood risk perception research by Kellens et al. (2012) indeed observes that a lack of knowledge about floods is associated with lower individual flood risk perceptions.

\section{Level of concern}

We want to examine whether different levels of concern among interviewees correlate to differences in perspectives on extreme weather. The (self-reported) information about climate change was identified as a factor influencing concern with respect to climate change (Kellstedt et al. 2008): the more individuals felt they were informed about climate change, the less concerned they were. Kellstedt et al. 
(2008) explain this by suggesting that those more informed about climate change probably also trust science and scientists to find a solution for climate change.

\section{Method}

Methodological framework

The methodology used in this paper is a non-steering open interview technique called repertory grid technique, introduced in construct psychology (Kelly 1955), and more recently applied in environmental studies (van der Sluijs et al. 2001; van de Kerkhof et al. 2009). The repertory grid technique uncovers the bipolar constructs that individuals use to understand and relate to a topic, here extreme weather events. The identification of these constructs, or perspectives, can be elicited by the interviewees themselves, using as probing devices the so-called elements: instances of the topic under investigation. As elements in the subsequent study, we selected fifteen photographs of extreme weather events and their impacts, shown in Fig. 1. We used photographs, because they convey more information to the respondents than sentences or words. Thus, the expected constructs could be more complex and varied.
The photographs were selected by the team and are representative of the extreme weather events expected in the Netherlands. In addition, to facilitate bottom-up elicitation, we tried to be as broad in our choice as possible, for instance having photographs depicting both urban environment (Photograph 2) as well as country side (Photograph 11, Photograph 15); also having photographs depicting problems (e.g., Photograph 5) as well as possible opportunities (Photograph 12). Further, some photographs were selected with an eye to the specific sectors we wanted to investigate, for instance Photographs 6 and 7 relate to transportation, Photograph 12 relates to the hospitality sector. Practical reasons (high resolution, clear colors, size) also played a role in the selection process.

Previous research suggests that 15-25 interviews can bring about saturation of unique constructs (Dunn 2001), as there is, according to the underlying theory, a limited amount of constructs individuals use for any given topic (Fransella et al. 2004). Another advantage of the method is the bottom-up elicitation of the constructs, using as only probe from the interviewer the elements (be it photographs, as in our case, words, sentences, etc.).

\section{Procedure}

During the interview, each respondent was asked to select three random photographs, facing upside-down, and to

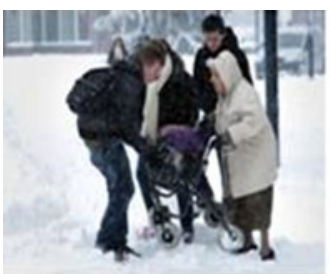

Photo 1

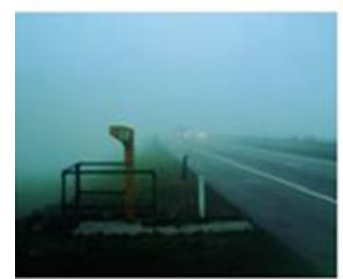

Photo 6

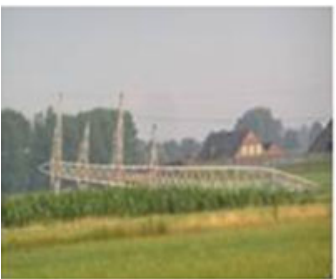

Photo 11

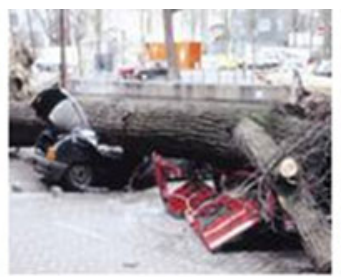

Photo 2

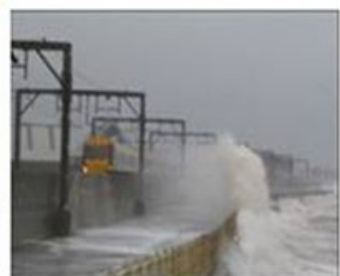

Photo 7

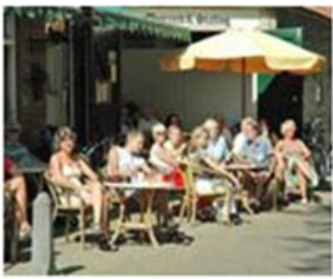

Photo 12

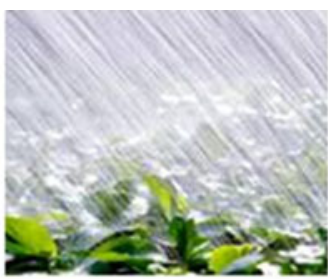

Photo 3

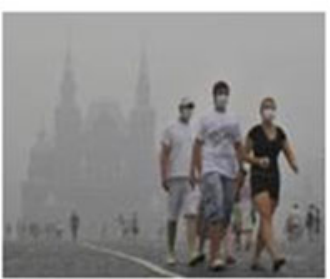

Photo 8

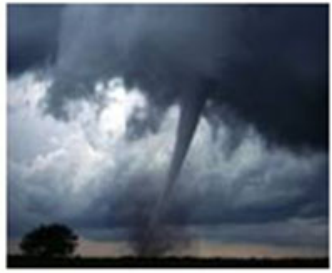

Photo 13

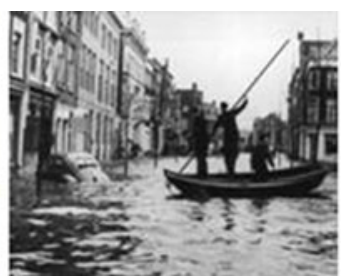

Photo 4

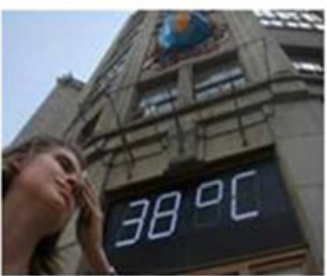

Photo 9

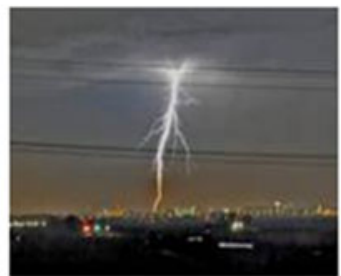

Photo 14

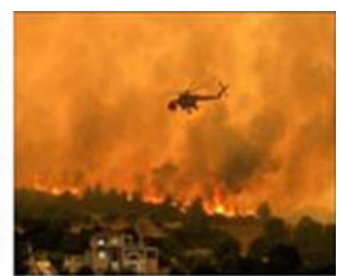

Photo 5

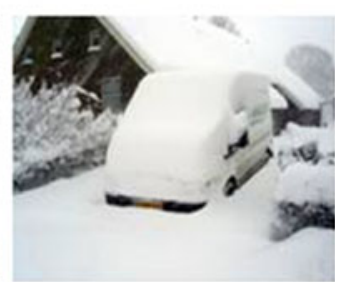

Photo 10

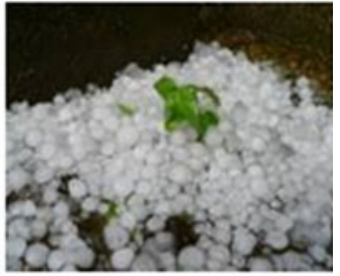

Photo 15

Fig. 1 Photographs of extreme weather and their impacts, used as elements for the repertory grid 
compare them, the question being: "To what extent are two of these phenomena similar and different from the third?" The answer to this question provided a bipolar construct, such as "no economic impact-great economic impact." The respondents were allowed to come up with more than one answer to a particular set of photographs, thus allowing multiple constructs to be identified by a single triplet of photographs. This process went on until the photographs were finished, and the respondent had no constructs to add. The respondent was then invited to select the three constructs that he/she considered the most important, "taking into account adaptation to extreme weather events." Following this selection, the respondent ranked all photographs (elements) on a 1-7 scale, according to their position in each of the three prioritized constructs. So if the construct was "no economic impact versus great economic impact," the scale would be $1=$ "no economic impact," $7=$ "great economic impact," and all the photographs would be given a number between 1 and 7 by the interviewee.

In addition, the respondents were asked a number of additional questions on their self-reported level of information about extreme weather, their level of concern about extreme weather, as well as their involvement in prior events and workshops related to climate change or extreme weather events. We did not ask any questions related to the nature of the communication events they participated.

\section{Analysis}

First, we conducted factor analysis (Principal Component Analysis-PCA) of the prioritized constructs against the rankings of the fifteen photographs (rows), to identify the perspectives on extremes. PCA is the standard method to analyze numerical repertory grid data (Fransella et al. 2004; Jankowicz 2004).

Second, we identified whether the sectors, the level of concern (1-7 scale), the level of information (1-7 scale) and participation in prior events (yes-no) were shaping the different perspectives that emerged. We used the percentages of constructs in these categories (each sector, level of information, etc.) to provide an indication of the random distribution.

\section{Sectors and participants}

We focused on the following sectors (number of interviewees from each sector in parenthesis): public health (6), crisis management (5), water sector (6), hospitality sector (hotels, restaurants and cafes) (6), tourism and recreation (9), urban transportation (5), vulnerable individuals (small children and older people) (4). The first three sectors were selected because of their primary role in responding to extreme weather events and are thus involved in adaptation to extreme events through their expertise. The following three (hospitality, urban transport and tourism and recreation) are economically vital sectors for urban areas in the Netherlands, especially Amsterdam, that are affected by extreme weather events. Vulnerable individuals were examined because they are among the most affected in the case of any extreme weather event (young children, older citizens); yet, because of lack of formal organization, they are rarely taken into account as social actors. We interviewed two individuals from organizations focused on small children below the age of four (organization for childcare facilities; organization for small children and public health), and two pensioners (a representative of an older people's association and a pensioner engaged in community work in the neighborhood).

Previous research has suggested that a person's physical location was an important determinant of climate change risk perception, especially given the fact that climate change impacts will be highly regional (Brody et al. 2008). Most of our interviewees work in, or close to, the city of Amsterdam, and thus, the perspectives tend to be urban. For instance, there was only no construct related to impact of extreme weather on agriculture.

The selection of sectors or interviewees in the sector did not follow the logic of representative sampling. The selection of the sectors was, on the one hand, related to our aim for designing adaptation strategies, as we made sure all relevant sectors were involved (e.g., crisis management). In addition, we tried to ensure the "maximum variety" within each sector by interviewing directors of institutes and simple employees alike. Our strategy is similar to that in previous studies of repertory grid (Home et al. 2010). We contacted relevant organizations and actors from the selected sectors at random, explaining the purpose of the study and the procedure. We interviewed the individuals that were interested in participating and contacted us back. This may have created a bias toward participants who were interested in the topic (adaptation to extreme events).

The interview protocol and the repertory grid were first piloted using four environmental studies researchers as interviewees. This allowed us to adjust the phrasing in some questions and change some of the photographs. The interviews took place in March-June 2011. We note that the preceding winter had been extremely cold in the Netherlands, and especially the month of January with long period of snowfall. This may have played a role in the identification of some constructs, due to the availability heuristic, through which interviewees remember well weather extremes they experienced recently (Tversky and Kahneman 1974). However, the variety in the extremes in the photographs, and the random selection of photographs is expected to minimize the impact of the availability heuristic. 
Table 1 Typology of perspectives on extreme events, based on PCA

\begin{tabular}{llll}
\hline Component & \% of variance & Initial eigenvalues \\
\hline Component 1 & 16 & Perspectives & 31.9 \\
Component 2 & 15 & New versus old weather extremes & 26.2 \\
Component 3 & 12 & Prepare for (material) damage & 11.5 \\
Component 4 & 12 & People involved & 10.2 \\
Component 5 & 12 & Beyond imagination & 7.3 \\
Component 6 & 6 & Natural resources management & 6.7 \\
\hline
\end{tabular}

${ }^{a}$ Rotation sums of Squared loadings

\section{Results}

Here, we first present the results of the statistical analyses (PCA), which aim to identify the different perspectives. The next section examines the determinants of differences in perspectives.

Factor analysis

The analysis in this section was conducted with PCA (Varimax Rotation) on the 121 ranked constructs against all 15 photographs (elements).

We focus on the first six components out of the total fourteen, which explain for $73 \%$ of the variance. Table 1 shows the labels we give to these components, which provide the operationalization of our perspectives. Their interpretation is given below, based on the constructs that loaded high on each component. Each perspective (component) includes the following elements: (a) typical character of the event; (b) typical kind of impact and (c) some notion of (need for) action to be taken.

Perspective 1, "Very disastrous, rescue needed," contains 21 constructs $^{1}$ that were brought up by 12 interviewees. The typical event in this perspective is sudden, very disastrous and dangerous. It is described as "violent," something you cannot do anything about, as opposed to peaceful and calm. Such an event is likely to have a short duration, and its impacts are typically local; it is more disastrous and long-lasting when it affects a city rather than the countryside. Its victims are in despair and afraid; they do not see a solution. This is not a nice place to visit, and the local hospitality sector is expected to lose a lot of customers. Interestingly, this type of events does not relate to serious (long term) health risks. Its focus is on sudden catastrophe with victims in need of urgent help (rescue). Exemplary constructs here are "very disastrous versus least disastrous"; "rescue needed fast versus help can wait"; "violent versus peaceful and calm", "short-term event versus long-term event".

\footnotetext{
${ }^{1}$ We take into account constructs that load 0.6 or higher in each component.
}

Perspective 2, labeled as "New versus old extremes", contains 16 constructs, mentioned by 13 interviewees. This component turns out to be very stable in the analysis: if we manipulate (e.g., diminish) the number of factors, this component comes out again. The perspective concentrates on the differences between extreme hot (summer, dry) and extreme cold (winter, wet) weather. The typical feature of annoying winter weather is its impact on transportation, namely that it gets slippery. This impact may be longlasting, but people normally would not need help. We are acquainted with this type of weather extremes. On the contrary, extreme heat is (as for the Netherlands) a relatively recent phenomenon, which people are not familiar with and which causes drought and health problems, especially during summer. It is the type of event where help is needed. Moreover, whereas extreme cold is associated with just one array of problems (constraints on transport), extreme heat is associated with 'multiple themes'. The interviewees did not come up with specific examples of measures or options that would address 'multiple themes' weather extremes. Typical constructs in this component are "high temperatures, heat versus low temperatures, cold"; "no impact on transportation versus maximum impact on transportation"; "happens the recent years versus happens since long."

Perspective 3 is labeled "Prepare for (material) damage" and includes 12 constructs, brought up by 8 interviewees. In some ways, it contrasts with perspective 2 as it focuses on typical Dutch weather extremes, especially storms. Storms and many other weather extremes are caused by nature rather than humans, and they can have dangerous consequences, as they cause damage to infrastructure and buildings. Many of the impacts cannot be dealt with at personal level, some of them can. Hence, preparatory measures need to be taken in so far this is possible, for example, the protection of infrastructure or stronger building regulations. Exemplary constructs in this perspective are "damage to electricity versus no damage to electricity"; "we need to prepare in advance versus no need to prepare"; "cases maximal damage versus causes no damage."

Perspective 4, labeled as "People involved," consists of 10 constructs, mentioned by 4 interviewees. This 
perspective is different from the others as it does not concentrate on any particular type of event, for example (sudden), storm or heat wave, nor on any particular type of human reaction (e.g., fear). It focuses on extreme events that occur infrequently and are dangerous in terms of their impacts. In contrast to perspective 3, this perspective acknowledges that many weather extremes or their impacts are more or less induced by humans. The involvement of persons is central in this argument, even though in different roles. Although it recognizes persons in their capacity of bringing help, it considers people primarily as victims. In fact, it distinguishes different types of impacts on (groups of) people like health risk, people threatened in their home environment, social disruption and, simultaneously, severe impact on nature. Exemplary constructs here are "health impacts versus no health impacts"; "induced by humans versus not induced by humans"; "people respond with help versus no response with help."

Perspective 5, which we labeled "Beyond Imagination," includes 13 constructs, mentioned by 8 interviewees. Like perspective 4 , it focuses on extreme events that happen infrequently. They are supposed to be catastrophic disasters, because of their dangerous consequences, that is, their impact on the daily lives of people and the huge costs of material damage. Some of the weather extremes are not (yet) known (in the Netherlands). But even if they are known, people hardly take them into account in their daily outdoor activities. In a sense, it is difficult to interpret the unique message hidden in this component. On the one hand, we learn that people might try to prepare themselves, if they would be aware of the things going to happen. On the other hand, however, it maybe anyhow impossible to intervene in an event that is beyond imagination. Typical constructs in this perspective are "extreme versus not extreme"; "complete disaster versus pleasant circumstances"; "not possible to intervene versus possible to intervene."

Perspective 6, "Natural resources management" includes 5 constructs, brought up by 3 interviewees. Neither of these specifies the extreme weather events themselves. Three relate to problems that extreme events can cause as regards natural resources, that is, water shortage, flooding and threat to food production. In these cases, spatial planning requires complex (as opposed to simple) adaptation measures. Exemplary constructs in this perspective are "related to water (shortage) versus not related to water (shortage)"; "threat to food production versus no threat to food production"; "spatial management needed versus no spatial management needed."

Table 2 presents the photographs that ranked the highest and the lowest in each perspective: these help contextualize the perspectives.
Determinants of perspectives

We tested as determinants of these perspectives the sector, level of concern, level of information and the prior participation to events. Concern and information were measured on a 1-7 scale; we re-coded both variables as BA (=Below Average and Average) values 1-4; and AA (=Above Average) values 5-7. In the cells, we indicate the percentage of constructs mentioned by respondents which had above average level of concern and above average level of information.

Table 3 presents the additional analyses. Column 2 shows the sectors of the respondents that mentioned constructs which loaded higher than 0.6 in each component. In column 3 , we group together the sectors that are primarily affected by weather extremes (urban transport, hospitality sector, tourism, vulnerable individuals) versus the sectors that primarily respond to extreme events (crisis management, public health, water sector). Column 4 shows the percent of constructs brought up by interviewees with above average level of concern, which were in total $44 \%$. Column 5 shows the percent of constructs mentioned by interviewees with above average level of information, which were in total $55 \%$. Column 6 shows the percent of constructs mentioned by interviewees with prior participation in events related to climate change or extreme weather events, which were in total $41 \%$. In the last three columns, we use bold typeset to indicate the numbers well above or below the percentage expected.

Table 3 suggests that all four variables (sectors, level of concern, level of information and prior participation in events) play a role in the identified perspectives, albeit to a different extent. With respect to the different sectors, most perspectives are cross-sectoral, but some sectors are represented more than others. Perspective 4, which relates to the involvement of people, either as victims or in their capacity to provide help, is, expectedly, comprised mostly by constructs from individuals in the crisis and water sectors, whose jobs related to saving human lives (crisis), and health risks (water sector). Surprisingly enough, constructs from the public health sector are absent in that perspective. The sixth perspective related to impacts on natural resources management is comprised exclusively from constructs of interviewees in the health sector, which makes it the only component from one sector. In perspectives 1, 3 and 5, sectors do not seem the defining factor shaping the components identified.

More informative than the actual sectors is the distinction whether individuals are primarily affected by extreme weather or have to respond with professional action. In the first two perspectives, individuals who are mostly affected by extreme weather are over-represented. Professionals responding to extreme weather events were, naturally, 
Table 2 Photographs ranked high and low for each perspective

\begin{tabular}{lll}
\hline Perspective & Ranks the highest & Ranks the lowest \\
\hline Perspective 1 & Photograph 13; photograph 5 & Photograph 12; photograph 9 \\
Perspective 2 & Photograph 9 & Photograph 10; photograph 1 \\
Perspective 3 & Photograph 11; photograph 13; photograph 2 & Photograph 6; photograph 12 \\
Perspective 4 & Photograph 8; photograph 5 & Photograph 12; photograph 14 \\
Perspective 5 & Photograph 5; photograph 4 & Photograph 12; photograph 1 \\
Perspective 6 & Photograph 4 & Photograph 11; photograph 2 \\
\hline
\end{tabular}

Table 3 Determinants of differences in perspectives

\begin{tabular}{|c|c|c|c|c|c|}
\hline & Sectors & $\begin{array}{l}\text { Relation to extreme } \\
\text { weather }\end{array}$ & $\begin{array}{l}\text { Concern } \\
(\mathrm{AA}=44 \%)\end{array}$ & $\begin{array}{l}\text { Information } \\
(\mathrm{AA}=55 \%)\end{array}$ & $\begin{array}{l}\text { Prior event } \\
(\text { Yes }=41 \%)\end{array}$ \\
\hline Perspective 1 & $\begin{array}{l}\text { Tourism } 7 \text {; hospitality } 5 \text {; vulnerable } 6 \text {; } \\
\text { crisis } 2 \text {; water } 1\end{array}$ & $\begin{array}{l}\text { Affected } 18 \\
\text { Responding } 3\end{array}$ & $57 \%$ & $29 \%$ & $14 \%$ \\
\hline Perspective 2 & $\begin{array}{l}\text { Hospitality } 2 \text {; transport } 4 \text {; tourism } 4 \text {; } \\
\text { health } 3 ; \text { crisis } 2 ; \text { vulnerable } 1\end{array}$ & $\begin{array}{l}\text { Affected } 11 \\
\text { Responding } 5\end{array}$ & $71 \%$ & $59 \%$ & $24 \%$ \\
\hline Perspective 3 & $\begin{array}{l}\text { Tourism } 4 \text {; transport } 3 \text {; health } 1 \text {; water } 2 \text {; } \\
\text { crisis } 2\end{array}$ & $\begin{array}{l}\text { Affected } 7 \\
\text { Responding } 5\end{array}$ & $25 \%$ & $42 \%$ & $8 \%$ \\
\hline Perspective 4 & Crisis 4 ; water 3 ; tourism 3 & $\begin{array}{l}\text { Affected } 3 \\
\text { Responding } 7\end{array}$ & $\mathbf{0} \%$ & $80 \%$ & $100 \%$ \\
\hline Perspective 5 & $\begin{array}{l}\text { Water } 5 \text {; hospitality } 3 \text {; tourism } 3 \text {; } \\
\text { transport } 1 \text {; health } 1 \text {; }\end{array}$ & $\begin{array}{l}\text { Affected } 7 \\
\text { Responding } 6\end{array}$ & $62 \%$ & $77 \%$ & $78 \%$ \\
\hline Perspective 6 & Health 4 & Responding 4 & $\mathbf{0} \%$ & $60 \%$ & $60 \%$ \\
\hline
\end{tabular}

over-represented in perspective 4 , about the role of humans involved, as well as the last perspective on natural resources management.

With respect to the level of concern, interviewees with above average level of concern for extreme weather events score a lot of constructs on the components related to "New versus old weather extremes" (component 2) and "Beyond imagination" (component 5). The high level of concern would relate, in that case, to extreme heat waves (component 2) and to unimaginable disasters (such as flood, fire because of heat wave and hurricane). The perspectives "People involved" and "Natural resources management" are comprised exclusively of constructs from interviewees with below average level of concern. In general, the level of concern plays a more important role in differences between the perspectives, than sectors.

The level of information seems to play a less important role in the shaping of perspectives. Highly informed individuals are overrepresented in the perspectives "People involved," as discussed above, and "Beyond imagination."

Finally, participation in prior events seems to be the most influential factor in the shaping of perspectives. Interviewees with prior participation in previous workshops are underrepresented in the first three perspectives, comprised of relatively common sense categories, whereas they are overrepresented in the last three perspectives which go beyond common knowledge and ways of thinking about extreme weather events. It is, however, noteworthy that they are also underrepresented in the perspective which is mostly concerned with the need to prepare (perspective 3 ).

\section{Discussion}

In this paper, we investigate the perspectives on extreme weather events that are prioritized with respect to adaptation by different social actors in the Netherlands, and the extent to which different actor characteristics correlate to differences in these perspectives. We identify six prevalent perspectives which interviewees prioritize for adaptation to extreme weather events: (1) very disastrous, rescue needed; (2) new versus old extremes; (3) prepare for (material) damage; (4) persons involved; (5) beyond imagination; and (6) natural resource management.

These perspectives link-specific events, or types of event, with their impacts, as well as with human action that is, or is not, needed (i.e., preparation, rescue). The priorities for human action for adaptation, coming out of these components, are primarily: immediate help and crisis management, in the case of very disastrous and 
catastrophic events, such as intense storms (perspective 1); addressing heat waves and drought, which we know little about and they are relatively recent (perspective 2); preparing infrastructure such as buildings as much as possible for extremes (perspective 3); addressing events that endanger human lives and have victims (perspective 4); and complex adaptation measures related to water (shortage) as changes in natural resource management and spatial planning (perspective 6). Each perspective, therefore, prioritizes different type of human action for adaptation to extreme event. That means that adaptation to extreme events resembles an unstructured problem, and robustness of adaptation strategies, as strategies reflecting different perspectives, is not a straightforward issue. Reconciliation among different perspectives may not always be possible, and we need to be aware of the fact that there may be winners and losers in adaptation strategies, as robust, winwin strategies that cut across all perspectives may be impossible.

Our results indicate that differences among the perspectives cannot be reduced to differences in economic sectors. Our concern with involving different sectors in adaptation governance and focusing on sectors to create societal awareness may be too limiting as a strategy. Instead, our results indicate that we need to involve actors with different underlying perspectives, in order to attempt to bridge some differences where possible.

Differences in perspectives were related to a broader link with extreme events: sectors mainly affected versus sectors mainly responding professionally to extreme weather. In the first two perspectives, individuals who are mostly affected by extreme weather are over-represented. We can imagine that for vulnerable individuals and sectors, the extent to which rescue is needed (perspective 1) is of vital importance, whereas professionals who respond with rescue in such cases probably feel that this is not priority for adaptation, because they already have a role in responding and rescuing during these circumstances. For the second perspective, we can also understand that professionals who have to respond to extreme weather are probably more knowledgeable with respect to "new, more recent" extremes, such as heat waves, and thus did not prioritize this perspective.

The level of concern was also relevant to understand the differences between perspectives. The perspectives "People involved" and "Natural resources management" are comprised exclusively of constructs from interviewees with below average level of concern. It can be the case that people with low degree of personal concern focus on the importance of "impersonal" adaptation measures (related to natural resources management). But the fact that these individuals also score low on focus on personal involvement and impacts on people (perspective 4) makes us think that the personal impacts of extreme weather events in perspective 4 are mentioned in a somewhat professional and detached manner from individuals with a lot of knowledge and prior participation to dedicated events.

In addition, individuals with high level of concern tend to prioritize more descriptive perspectives (cold vs. hot; level of extremity) and not prioritize more elaborate perspectives (i.e., health and societal impacts; level of complexity of adaptation measures). It could be the case that individuals, who feel more than average concerned, feel concerned because they lack more elaborate knowledge on extreme weather events. In a previous study, it was found that the number of information sources one is exposed to is positively linked to perceived level of preparedness (Basolo et al. 2009). Individuals who participate thus in such events may feel more prepared, and thus less concerned, than individuals who do not participate in such events.

The level of self-reported information seems to play a less important role in the shaping of components than the level of concern. Highly informed individuals are overrepresented in the components related to societal and health impacts, as well as level of extremity, and economic costs. It could be the case that these two components are more related to more elaborate knowledge about extreme weather. It could also be the case that level of concern and information is linked in a different way: people who focus on impacts on human lives and health (perspective 4) will inform themselves better than people who mainly worry about less-far-reaching consequences.

Finally, participation in prior events seems to be the most influential factor in the shaping of perspectives. Interviewees with prior participation in workshops are underrepresented in descriptive, common sense perspectives, whereas they are overrepresented in the more elaborate perspectives. These interviewees may have thus been primed through their participation, in drawing on elaborate perspectives. Our original expectation that individuals with prior participation to such events would tend to draw on formal knowledge and prioritize more elaborate perspectives seems to be confirmed.

With respect to the role of education, organization of workshops and dissemination of knowledge about extreme weather events, the results point to some interesting insights. Individuals who participate in events, workshops or lectures, etc. on climate change or extreme weather events are underrepresented in some components and especially the component related to the need to prepare in advance for the possibility of extreme weather. This could be linked to the increased sense of preparedness that additional information sources provide, as found by previous studies (Basolo et al. 2009). Many such events have the implicit intention of mobilizing for adaptation and preparedness to extreme weather events. This, however, should not be taken for granted. 
The emphasis of our study on perspectives as opposed to risk perceptions was successful. The interviewees were less inclined to answer on the basis of heuristics and biases. In addition, it becomes clear that the way individuals relate to extreme weather is much more complex than estimating how high the risks of its impact will be. We suggest that communication events, as well as interaction between stakeholders and policymakers on defining adaptation priorities should start by investigating the underlying perspectives of the participants. This would provide a firm ground on which constructive conflict methodologies can be used, given the differences in perspectives (Cuppen 2012). Repertory grid analysis proved useful in this, since it facilitated bottom-up elicitation of these perspectives.

The results of the study should be read with care. Our interviewees could be more concerned or knowledgeable about extreme weather events, than a random sample of the Dutch population. In the invitation for the interviews, we indicated the topic of the research, and one could expect that those agreeing to participate may have had some interest in extreme weather events, either by having knowledge about it, or either by feeling concerned about it. This does not invalidate our results, however, because close to half of our individuals reported above average level of information and above average level of concern. The number of interviews we conducted ensures a saturation point of constructs, since 15-25 interviews are enough to capture the entirety of different constructs, according to previous repertory grid analyses.

Further analysis needs to be conducted, to link how different communication strategies can target each of these underlying perspectives, so that scientific and policy-relevant information on adaptation to extremes can be successfully communicated to different social actors. However, we cannot take for granted that this information will actually lead to behavioral change (McEvoy et al. 2010), nor to change of the underlying perspectives. As other unstructured problems, designing robust adaptation strategies may come about through constructive conflict, rather than reconciliation.

Acknowledgments Research underlying this paper was funded by the Netherlands Organization for Scientific Research (NWO) and Programme Knowledge for Climate (Kennis voor Klimaat), project number 830.10.005.

Open Access This article is distributed under the terms of the Creative Commons Attribution License which permits any use, distribution, and reproduction in any medium, provided the original author(s) and the source are credited.

\section{References}

Basolo V, Steinberg LJ, Burby RJ, Levine J, Cruz AM, Huang C (2009) The effects of confidence in government and information on perceived and actual preparedness for disasters. Environ Behav 41(3):338-364
Battaglini A, Barbeau G, Bindi M, Badeck F-W (2009) European winegrowers' perceptions of climate change impact and options for adaptation. Reg Environ Change 9:61-73

Brody SD, Zahran S, Vedlitz A, Grover H (2008) Examining the relationship between physical vulnerability and public perceptions of global climate change in the United States. Environ Behav 40(1):72-95

Buys L, Miller E, van Megen K (2012) Conceptualising climate change in rural Australia: community perceptions, attitudes and (in) actions. Reg Environ Change 12(1):237-248

Cuppen E (2012) Diversity and constructive conflict in stakeholder dialogue: considerations for design and methods. Policy Sci 45(1):23-46

de Boer J, Wardekker JA, van der Sluijs JP (2010) Frame-based guide to situated decision-making on climate change. Glob Environ Change 20(3):502-510

de Bruin K, Dellink RB, Ruijs A, Bolwidt L, Av Buuren, Graveland J, Groot RSd, Kuikman PJ, Reinhard S, Roetter RP, Tassone VC, Verhagen A, Ierland ECv (2009) Adapting to climate change in The Netherlands: an inventory of climate adaptation options and ranking of alternatives. Clim Change 95:23-45

Dessai S, Hulme M (2004) Does climate adaptation policy need probabilities? Clim Policy 4:107-128

Dessai S, Adger WN, Hulme M, Turnpenny J, Köhler J, Warren R (2004) Defining and experiencing dangerous climate change. Clim Change 64(1-2):11-25

Dunn W (2001) Using the method of context validation to mitigate Type III errors in environmental policy analysis. In: Hisschemoller M, Hoppe R, Dunn W, Ravetz J (eds) Knowledge, power and participation in environmental policy analysis. Transaction Publishers, New Jersey, pp 417-436

Eakin HC, Patt A (2011) Are adaptation studies effective, and what can enhance their practical impact? Wiley Interdiscip Rev Clim Change 2(2):141-153

Ford JD, Pearce T, Prno J, Duerden F, Ford LB, Beaumier M, Smith T (2010) Perceptions of climate change risks in primary resource use industries: a survey of the Canadian mining sector. Reg Environ Change 10:65-81

Fransella F, Bell R, Bannister D (2004) Manual for repertory grid technique, vol 2. Wiley and Sons, Chichester

Hisschemöller M (2005) Participation as knowledge production and the limits of democracy. Soc Sci Yearb 24:189-208

Hisschemöller M, Midden CJH (1999) Improving the usability of research on the public perception of science and technology for policy-making. Public Underst Sci 8(1):17-33

Home R, Bauer N, Hunziker M (2010) Cultural and biological determinants in the evaluation of urban green spaces. Environ Behav 42(4):494-523

Hoppe R, Hisschemöller M (2001) Coping with intractable controversies: the case for problem structuring in policy design and analysis. In: Hisschemöller M, Hoppe R, Dunn W, Ravetz J (eds) Knowledge power and participation in environmental policy analysis. Transaction Publishers, New Brunswick, pp 47-72

IPCC (2011) Summary for Policymakers. In: Field CB, Barros V, Stocker TF et al (eds) Intergovernmental panel on climate change special report on managing the risks of extreme events and disasters to advance climate change adaptation. Cambridge University Press, Cambridge

Jankowicz D (2004) The easy guide to repertory grids. Wiley, Chichester

Kellens W, Terpstra T, Maeyer PD (2012) Perception and Communication of Flood Risks: A Systematic Review of Empirical Research. Risk Anal doi:10.1111/j.1539-6924.2012.01844.x

Kellstedt PM, Zahran S, Vedlitz A (2008) Personal efficacy, the information environment, and attitudes toward global warming and climate change in the United States. Risk Anal 28(1): $113-126$ 
Kelly JA (1955) The psychology of personal constructs I. II. W. Norton, New York

Keskitalo ECH, Westerhoff L, Juhola S (2012) Agenda-setting on the environment: the development of climate change adaptation as an issue in European states. Environmental Policy and Governance online. doi:10.1002/eet.1579

Katsman CA, Sterl A, Beersma JJ, van den Brink HW, Church JA, Hazeleger W, Kopp RE, Kroon D, Kwadijk J, Lammersen R, JL, Oppenheimer M, Plag H-P, Ridley J, von Storch H, Vaughan DG, Vellinga P, Vermeersen LLA, van de Wal RSW, Weisse R (2011) Exploring high-end scenarios for local sea level rise to develop flood protection strategies for a low-lying delta-the Netherlands as an example. Clim Change. doi:10.1007/s10584011-0037-5

Lowe TD, Lorenzoni I (2007) Danger is all around: eliciting expert perceptions for managing climate change through a mental models approach. Glob Environ Change 17(1):131-146

McEvoy D, Matczak P, Banaszak I, Chorynski A (2010) Framing adaptation to climate-related extreme events. Mitig Adapt Strateg Glob Change 15(7):779-795

Meehl GA, Covey C, Delworth T, Latif M, McAvaney B, Mitchell JFB, Stouffer RJ, Taylor KE (2007) The WCRP CMIP3 multimodel dataset: a new era in climate change research. Bull Am Meteorol Soc 88:1383-1394

Otto-Banaszak I, Matczak P, Wesseler J, Wechsung F (2011) Different perceptions of adaptation to climate change: a mental model approach applied to the evidence from expert interviews. Reg Environ Change 11:217-228

Pahl-Wostl C (2002) Participative and stakeholder-based policy design, evaluation and modelling processes. Integr Assess $3: 3-14$

Patt AG, Schröter D (2008) Perceptions of climate risk in Mozambique: implications for the success of adaptation strategies. Glob Environ Change 18(3):458-467

Reyer C, Bachinger J, Bloch R, Hattermann FF, Ibisch PL, Kreft S, Lasch P, Lucht W, Nowicki C, Spathelf P, Stock M, Welp M (forthcoming) Climate change adaptation and sustainable regional development: a case study for the Federal State of Brandenburg, Germany. Reg Environ Change. doi: 10.1007/ s10113-011-0269-y

Rosenzweig C, Solecki WD, Blake R, Bowman M, Faris C, Gornitz V, Horton R, Jacob K, LeBlanc A, Leichenko R, Linkin M,
Major D, O’Grady M, Patrick L, Sussman E, Yohe G, Zimmerman R (2011) Developing coastal adaptation to climate change in the New York city infrastructure-shed: process, approach, tools, and strategies. Clim Change 106(1):93-127

Runhaar H, Mees H, Wardekker A, van der Sluijs J, Driessen PPJ (forthcoming) Adaptation to climate change-related risks in Dutch urban areas: stimuli and barriers Reg Environ Change. doi:10.1007/s10113-012-0292-7

Taylor JG, Stewart TR, Downton M (1988) Perceptions of drought in the ogallala aquifer region. Environ Behav 20(2):150-175

Terpstra T, Lindell MK, Gutteling JM (2009) Does communicating (flood) risk affect (flood) risk perceptions? Results of a quasiexperimental study. Risk Anal 29(8):1141-1155

Tversky A, Kahneman D (1974) Judgment under uncertainty: heuristics and biases. Science 211:1124-1131

Valkering P, Van der Brugge R, Offermans A, Rijkens-Klomp N (2011) Scenario analysis of perspective change to support climate adaptation: lessons from a pilot study on Dutch river management. Reg Environ Change 11:229-241

van de Kerkhof M, Cuppen E, Hisschemöller M (2009) The repertory grid to unfold conflicting positions: the case of a stakeholder dialogue on prospects for hydrogen. Technol Forecast Soc Change 76(3):422-432

Van den Hurk B, Tank AK, Lenderink G, van Ulden A, van Oldenborgh GJ, Katsman C, van den Brink H, Keller F, Bessembinder J, Burgers G, Komen G, Hazeleger W, Drijfhout S (2006) KNMI climate change scenarios 2006 for the Netherlands. KNMI Scientific Report WR 2006-01. KNMI, de Bilt

van der Sluijs JP, Hisschemoller M, de Boer J, Kloprogge P (2001) Climate risk assessment: evaluation of approaches; synthesis report. Dutch national research programme on global air pollution and climate change NW\&S-E-2002-96, Utrecht

Vasileiadou E (2012) Consulting stakeholders? Assessing stakeholder consultations in the European energy policy. In: Tortora M (ed) Sustainable systems and energy management at the regional level: comparative approaches. IGI Global, Hershey, pp 328-347

Vasileiadou E, Tuinstra W (2012) Stakeholder consultations in the energy directorate; Can they help integrate climate change? Environ Politics iFirst:1-21

Ziervogel G, Bharwani S, Downing TE (2006) Adapting to climate variability: pumpkins, people and policy. Nat Resour Forum 30(4):294-305 